Гармаев Ю. П. Устранение сомнений в допустимости доказательств // Законность. - 2011. - № 5. - С. 29-33.

Обновлена в связи с изм. Зак-ва на 1.05.14.

\title{
УСТРАНЕНИЕ СОМНЕНИЙ В ДОПУСТИМОСТИ ДОКАЗАТЕЛЬСТВ
}

\author{
Юрий Петрович Гармаев, \\ доктор юридических наук, профессор, \\ старший советник юстищии
}

Каждый прокурорский работник, кому доводилось не раз поддерживать обвинение по уголовному делу, помнит весьма неприятные ситуации, когда в судебных стадиях обнаруживаются нарушения закона и следственные ошибки, допущенные в ходе расследования и/или проведения, документирования оперативно-розыскных мероприятий (OPM). Часто такие нарушения и ошибки могут повлечь разрушение в суде всей системы доказательств обвинения или значительной ее части. Но дело уже направлено в суд (и не всегда тем лицом, кто участвует в процессе), а значит уже далеко не все можно исправить. В подобных ситуациях у каждого работника прокуратуры вслед за чувством досады и возмущения работой следователя, оперативного сотрудника, руководителя следственного органа, возникает профессионально-этическая проблема - согласиться с доводами стороны защиты, вплоть до отказа от обвинения, или сделать все возможное для «спасения дела в суде»?

Результаты специального анкетирования государственных обвинителей, проведенного автором в Иркутском институте повышения квалификации прокурорских работников Генпрокуратуры РФ ${ }^{1}$ в 2006-2007 г.г., показали решимость наших коллег «по возможности спасти дело», даже при многочисленных нарушениях закона в досудебной стадии. Так ответили около $100 \%$ из 350-ти анкетированных. Вместе с тем респонденты отмечали важное условие: «Если только я субъективно убежден (а), что подсудимый виновен в преступлении».

Но если государственный обвинитель в подобной ситуации твердо решил поддерживать обвинение, а собственного опыта и знаний хватает не у каждого, то где найти научно обоснованные и не противоречащие закону аргументы своей позиции?

В порядке краткой иллюстрации приведем типичные нарушения закона, допускаемые оперативными сотрудниками органов - субъектов оперативно-розыскной деятельности (далее - ОРД), по делам о взяточничестве (ст. 290-291 УК РФ) и другим.

- в нарушение ч. 7 ст. 8 Федерального закона от 12.08.1995 № 144-Ф3 «Об оперативно-розыскной деятельности» (Далее - ФЗ «Об ОРД»), 
постановление о проведении оперативного эксперимента утверждается ненадлежащим лицом (не руководителем органа, осуществляющего ОРД, а, например, руководителем подразделения органа);

- в документах, составляемых по результатам ОРМ, часто допускаются ошибки в названии оперативно-розыскного мероприятия. Например, «следственный эксперимент» вместо «оперативный эксперимент» (нарушение п. 14 ч. 1 ст. 6 Ф3 «Об ОРД»), и многие другие подобные нарушения.

Заметим, что подобные типичные нарушения закона на досудебной стадии, к счастью, объединяет особенность: большинство из них носит явно несущественный и устранимый характер. Однако повторим - в примерах с формальной точки зрения нарушение закона имеется. Отсюда позиция стороны защиты, а так же ряда ученых-процессуалистов, такова: ч. 2 ст. 50 Конституции РФ, запрещает использование доказательств, полученных с нарушением федерального закона, то есть любые процессуальные нарушения недопустимы ${ }^{2}$. Как справедливо заметил в этой связи В. П. Божьев: «Трудно сказать, чего в подобных суждениях присутствует больше: элементарного непонимания процесса, демагогии, лицемерия или юридического невежества?!» ${ }^{3}$.

Тем не менее, не только адвокаты - их процессуальный статус обязывает, но и некоторые судьи взяли на вооружение такой подход. Между тем отдельные государственные обвинители в нужный, а это чаще всего непредвиденный момент, не находят должных аргументов, не предпринимают активных действий по проверке и оценке доказательств, могущих вызвать у суда сомнения в допустимости. В результате заслуживающие строгого наказания субъекты часто избегают его, как уже отмечалось, по так называемым формальным основаниям.

Безусловно, проблемы нужно устранять, прежде всего, на предварительном следствии. Представители стороны обвинения должны активно предупреждать, пресекать и устранять любые нарушения закона и ошибки следствия. Нужно их не только выявлять, но и прогнозировать, предвидеть типичные выпады стороны защиты против доказательств обвинения.

Проще говоря, когда еще не поздно что-то предотвратить и устранить, следователь, дознаватель, руководитель следственного органа, надзирающий прокурор, иной представитель стороны обвинения должен принципиально и жестко реагировать на любые ошибки и нарушения, всеми силами бороться с непрофессионалами и нарушителями закона в своей среде.

Однако в случае если некоторые нарушения не были выявлены и устранены на досудебной стадии, государственный обвинитель при наличии законных оснований (выделено мной - Ю.Г.) вправе предложить суду признать допустимыми соответствующие доказательства. Для этого представителям стороны обвинения можно предложить апробированные аргументы, которые можно использовать государственному обвинителю в соответствующих типичных судебных ситуациях. 
Аргументы эти условно разделены на общие и частные. Общие аргументы имеют более универсальный характер в том смысле, что часто применяются по любой категории уголовных дел, в отношении практически всех видов доказательств. Их не должно быть много - здесь изложено 7. Частные аргументы многочисленны, но менее универсальны. Они разрабатываются и применяются по конкретным категориям дел.

Прежде всего, приведем общие аргументы, и по возможности изложим их так, как они, на наш взгляд, могут прозвучать в реальной судебной речи государственного обвинителя:

1) «Ваша честь! При проведении данного следственного действия допущено нарушение уголовно-процессуального закона. Однако следует ли считать его настолько существенным и неустранимым, что это повлечет признание доказательства недопустимым? Полагаю, что такой вывод не соответствовал бы смыслу закона и сложившейся судебной практике. В постановлении Пленума Верховного Суда РФ от 5 марта 2004 г. № 1 «О применении судами норм Уголовно-процессуального кодекса Российской Федерации» отмечается: «Когда в досудебном производстве были допущены существенные нарушения закона, не устранимые в судебном заседании... судья... возвращает дело прокурору для устранения допущенных нарушений» (здесь и далее курсив наш. - Ю.Г., А.К.). Подробное изучение этих разъяснений позволяет сделать вывод, что Верховный Суд РФ фактически вернулся ${ }^{1}$ к разграничению нарушений закона на несущественные и/или устранимые, в противовес существенным и/или неустранимым, предусматривая для них противоположные правовые последствия. Считаю, что в данном случае имеет место несущественное / устранимое нарушение, поскольку .........».

2)«Ваша честь! Конституционный Суд РФ определил существенное процессуальное нарушение как препятствие для рассмотрения дела, которое суд не может устранить самостоятельно и которое как повлекшее лишение или стеснение гарантируемых законом прав участников уголовного судопроизводства (выделено нами - авторы) исключает возможность постановления законного и обоснованного приговора и фактически не позволяет суду реализовать возложенную на него Конституцией РФ функцию осуществления правосудия ${ }^{2}$. Полагаю, что допущенное по настоящему делу нарушение следует признать несущественным, поскольку оно реально не повлекло лишение или стеснение гарантируемых законом прав участников уголовного судопроизводства, поскольку ..... Для проверки предлагаю ....».

3)«Ваша честь! Несущественные нарушения - это, прежде всего те,

\footnotetext{
1 Достаточно вспомнить ст. 345 УПК РСФСР «Существенное нарушение уголовно - процессуального закона». Подробный анализ этой проблемы дан в упомянутой выше работе В. П. Божьева.

2 п. 3 Постановления Конституционного Суда РФ от 8 декабря 2003 г. № 18-П «По делу о проверке конституционности положений статей $125,219,227,229,236,237,239,246,254,271,378,405$ и 408, а также глав 35 и 39 Уголовно-процессуального кодекса Российской Федерации в связи с запросами судов общей юрисдикции и жалобами граждан» // [Электронный ресурс] // Режим доступа: http: // www.ksrf.ru - Загл. с экрана. (дата обращения 17.06.2014).
} 
которые не повлияли и не могли повлиять на достоверность получаемого результата. К примеру, когда свидетель вызывается в суд способом, не указанным в ст. 188 УПК РФ, а скажем, через другого свидетеля ${ }^{3}$ Или, например, разве ошибка в наименовании документа «приговор» (пригавор, прегговор и т.п.), будучи несомненным нарушением УПК РФ, должна с необходимостью повлечь отмену судебного решения? Предлагаю проверить именно достоверность этого доказательства следующим образом .......».

4)Ваша честь! Часть 1 статьи 389.17 УПК РФ под существенными нарушениями уголовно-процессуального закона, являющимися основаниями отмены или изменения судебного решения судом апелляционной инстанции понимаются нарушения, которые путем лишения или ограничения гарантированных УПК РФ прав участников уголовного судопроизводства, несоблюдения процедуры судопроизводства или иным путем повлияли или могли повлиять на вынесение законного и обоснованного судебного решения.

По мнению авторов известного Вам авторитетного комментария к УПК РФ под редакцией профессоров В.М. Лебедева и В.П. Божьева ${ }^{4}$ в данной норме дано общее понятие не любых, а именно существенных нарушений УПК РФ. Авторы, не ограничиваясь теоретическим обоснованием, ссылаются на многочисленные примеры из опубликованной практики Верховного Суда РФ $\Phi^{5}$. Тем самым обосновывается то, что нарушения, которые не повлияли и не могли повлиять на законность, обоснованность и справедливость судебного решения должны считаться несущественными. Предлагаю в судебном заседании проверить, могут ли повлиять допущенные по настоящему уголовному делу нарушения на законность, обоснованность и справедливость предстоящего судебного решения? ....».

5. «Ваша честь! Оценку существенности допущенных нарушений следует давать не только с учетом ч. 2 ст. 50 Конституции РФ, но и с учетом позиции Пленума Верховного Суда РФ, выраженной в постановлении от 31.10.1995 № 8 "О некоторых вопросах применения судами Конституции РФ при осуществлении правосудия". В П. 16 указанного постановления отмечено, что доказательства должны признаваться полученными с нарушением закона, если при их собирании и закреплении были нарушены гарантированные Конституцией РФ права человека и гражданина или установленный уголовно-процессуальным законодательством порядок их собирания и закрепления, а также если собирание и закрепление доказательств осуществлено ненадлежащим лицом или органом либо в результате действий, не предусмотренных процессуальными нормами.

\footnotetext{
${ }^{3}$ Гришина Е. П., Саушкин С. А., Абросимов А. В. Дискуссионные проблемы допустимости доказательств в науке уголовно-процессуального права (теории "беспощадного исключения доказательств", "плодов отравленного дерева" и "асимметрии правил допустимости")" // Мировой судья. - 2008. - № 1. - С. 58-59.

${ }^{4}$ Научно-практический комментарий к уголовно-процессуальному кодексу Российской Федерации / под общ. ред. В.М. Лебедева, науч. ред. В.П. Божьев - 6-е изд., перераб. и доп. - М.: Изд-во Юрайт; ЮрайтИздат, 2010. - С. 968-970.

${ }^{5}$ В частности авторами даны следующие ссылки: БВС РСФСР. 1986. № 7. С. 3; 1989. № 1. С. 9; БВС РФ. 1994. № 5. С. 14; 1997. № 2. С. 18; БВС РФ. 2003. № 7. С. 16, № 8. С. 15 - 16, № 12. С. 19 - 20 и др.
} 
Разве в рамках анализируемого следственного действия были нарушены гарантированные Конституцией РФ права человека и гражданина?...... Прошу суд дать оценку ......».

6) «Ваша честь! Допущенное по настоящему делу и отмеченное стороной защиты нарушение закона вряд ли следует признавать существенным. Но даже если признать его таковым, оно во всяком случае вполне устранимо. Устранимыми, или восполнимыми должны признаваться нарушения, которые могут быть восполнены или нейтрализованы. К таким нарушениям относятся, как правило, дефекты процессуального оформления. К таковым могут быть отнесены отсутствие подписи, неуказание продолжительности времени производства следственного действия и т.п. Однако доказательство, полученное даже и с более серьезным нарушением закона, может быть восполнено в результате замены другим (в т.ч. аналогичным). Например, следственное действие может быть повторено (не разъяснены потерпевшему его процессуальные права - возможно допросить заново, но уже с разъяснением прав) ${ }^{6}$. Для устранения (нейтрализации) указанного нарушения предлагаю....».

7) В качестве аргумента в пользу допустимости любого из доказательств, полученных на основе результатов ОРД, но с отдельными нарушениями соответствующего Федерального закона (в частности, с тем нарушением, что было приведено выше), можно использовать следующее обоснование:

«Ваша честь! В соответствии с ч. 2 ст. 50 Конституции РФ не могут быть положены в основу обвинения доказательства, только именно полученные $\boldsymbol{c}$ нарушением закона. Но в ходе и по результатам ОРД доказательства не получают. Получают только сведения (п. 36-1 ст. 5 УПК РФ). Доказательства же формируются только в рамках процессуальных действий по возбужденному уголовному делу. Следовательно, буквальное толкование Конституции позволяет сделать вывод: нарушения Ф3 «Об ОРД» (равно как и иного законодательства) не должны с необходимостью повлечь недопустимость использования результатов ОРД в уголовном процессе. Предлагаю, прежде всего, проверить достоверность и относимость сведений - результатов ОРД, на основе которых было сформировано это доказательство (см. аргумент № 3). В частности, ходатайствую о .......».

Думается, что в судебном заседании государственному обвинителю начать свою речь необходимо именно с общих аргументов (с одного из приведенных или с нескольких). Далее, по необходимости, следует воспользоваться частными аргументами и рекомендациями о действиях государственного обвинителя в рамках проверки и оценки доказательств.

Так, частными аргументами по приведенному выше примеру (ненадлежащее лицо утвердило постановление о проведении ОРМ) могут быть следующие: 1) Ф3 «Об ОРД» гласит: «руководитель органа». Термин следует толковать в том значении, что руководителей может быть и несколько (например, первый руководитель и заместитель). 2) Часть 2 статьи

${ }^{6}$ Подробнее см.: Гришина Е. П., Саушкин С. А., Абросимов А. В. Указ. соч. - С. 60. 
9 данного закона определяет, что перечень руководителей, уполномоченных к подписанию отдельных документов, устанавливается ведомственными нормативными актами. Некоторые из них дают не односубъектный, а многосубъектный перечень должностных лиц.

Другой пример: сторона защиты обращает внимание суда на то, что к участию в оперативном эксперименте привлекались лица, которых назвали «понятыми», им разъясняли несуществующие права и обязанности. Кроме того, как это часто случается на практике, «понятой» оказался заинтересованным лицом либо не может быть допрошен, либо не помнит событие, не подтверждает обстоятельства, описанные в документах, и т.п.

Аргументы и действия в защиту обвинительных доказательств могут быть следующие:

Аргумент 1: Вообще нет нарушения законодательства об ОРД, поскольку в нем нет ни обязательного требования об участии «понятых», ни запрета на их участие. Поэтому дефекты, связанные с ними сами по себе не исключают признания допустимыми формируемых доказательств (в нашем случае - иных документов). Проверке и оценке подлежит не это, а достоверность сведений.

Аргумент 2: Действующая редакция ч. 1 ст. 15 Ф3 «Об ОРД» требует, что в случае изъятия документов, предметов, материалов при проведении гласных оперативно-розыскных мероприятий должностное лицо, осуществившее изъятие, составляет протокол в соответствии с требованиями уголовно-процессуального законодательства РФ. А значит в соответствующих случаях требуется участие понятых.

Аргумент 3: Ст. 17 Ф3 «Об ОРД» предусматривает содействие граждан органам, осуществляющим ОРД, но не детализирует степень, формы, условия их участия, критерии допустимости получаемых с их помощью сведений.

Действия: допрос оперативных сотрудников, участников ОРМ и руководителей. Цель здесь будет, прежде всего, в том, чтобы выяснить, достоверны ли события, описанные в документах (передача денег, их изъятие у взяткополучателя и т.п.). Если совокупностью доказательств подтверждается, что события описаны в документах достоверно, то уже безразлично, как названы присутствующие граждане и имеются ли какиелибо упущения в работе с ними.

Итак, одной из важных задач, решаемых государственным обвинителем в судебном разбирательстве, является защита обвинительных доказательств, в отношении которых у суда возникли или могут возникнуть сомнения в допустимости. Безусловно, далеко не во всяком случае у государственного обвинителя могут быть основанные на законе аргументы и действия в защиту доказательств. Часто те ошибки и нарушения, которые были допущены в стадии возбуждения дела и в ходе предварительного расследования настолько существенны и неустранимы, что исключается эффективность всякой попытки «спасти» их с позиции допустимости. 
И в то же время, в случае если сторона обвинения выявила и представила суду аргументированные доводы в пользу несущественности и/или устранимости той или иной ошибки, нарушения закона, у государственного обвинителя есть шанс добиться признания доказательств допустимыми 4 . Это вопрос процессуального спора сторон в суде. И победителем в данном споре становится тот, кто более профессионален и лучше подготовлен к процессу.

Пристатейный библиографический список:

1. Божьев В. П. Существенные нарушения норм УПК // Законность. - 2009. № $1 .-$ C. 24.

2. Злотых В. Проверка допустимости доказательств в уголовном процессе. Ростов н/Д: Изд-во «Феникс». - 1999.

3. Чувилев Н., Лобанов А. Плоды отравленного дерева // Российская юстиция. - 1996. - № 11.

4. Гришина Е. П., Саушкин С. А., Абросимов А. В. Дискуссионные проблемы допустимости доказательств в науке уголовно-процессуального права (теории "беспощадного исключения доказательств", "плодов отравленного дерева" и "асимметрии правил допустимости")" // Мировой судья. - 2008. - № 1.

5. Гармаев Ю.П., Обухов А.А. Квалификация и расследование взяточничества: учебно-практическое пособие. - М., Изд-во «Норма» 2009.

\footnotetext{
${ }^{1}$ В настоящее время - Иркутский юридический институт (филиал) Академии Генеральной прокуратуры РФ. Анкетирование проводилось в 2006 году, то есть до разделения функций прокурорского надзора и организации предварительного следствия, образования Следственного комитета при прокуратуре Российской Федерации.

2 В уголовно-процессуальной науке довольно много как противников, так и сторонников теории «беспощадного исключения доказательств». К числу последних можно отнести А. Лобанова, В. Золотых, В. Савицкого, Н. Чувилева и др. См., например: Злотых В. Проверка допустимости доказательств в уголовном процессе. - Ростов н/Д: Изд-во «Феникс». - 1999; Чувилев Н., Лобанов А. Плоды отравленного дерева // Российская юстиция. - 1996. - № 11. - С. 47 - 49, и др.

${ }^{3}$ Божьев В. П. Существенные нарушения норм УПК // Законность. - 2009. - № 1. - С. 24.

${ }^{4}$ Подробнее об этом см.: Гармаев Ю.П., Обухов А.А. Квалификация и расследование взяточничества: учебно-практическое пособие. - М., Изд-во «Норма» - 2009. - С. 145-151.
} 